\title{
LA FUENTE DE LA VENUS DE ARANJUEZ, OBRA DE FRANCISCO MOSCHINO
}

Hace unos años Martín González dio a conocer la documentación referente al envío desde Florencia de la fuente de la Venus del Jardín de la Isla de la Isla de Aranjuez por don García de Toledo .Desde Alicante llegan a Aranjuez el año de 1571 las cuarenta piezas de mármol que se correspondían a los elementos arquitectónicos y escultóricos de la fuente y la figura en bronce de una mujer secándose el cabello ${ }^{1}$ (figs. 1 y 2).Se discutió en su día su parecido con la figura de la Venus de Giambologna, obra del año de hacía 1570 que corona la fuente del Laberinto diseñada por Tribolo, conservada actualmente en Villa Petraia, aunque por la proximidad de las fechas en las que se realizan y las diferencias advertidas entre ambas quizás, como se dijo, pudieron tener una fuente común, el grabado de Marcantonio que precisamente invoca Avery como posible modelo de la fuente italiana ${ }^{2}$.

${ }^{1}$ Martín GonZÁlez, Juan José: El escultor en Palacio. Viaje a través de la escultura de los Austria, Madrid, 1991, 129.

2 Estella, Margarita "Sobre las esculturas del Jardín de la Isla en Aranjuez"Velázquez y el Arte de su tiempo. V Jornadas de Arte, Madrid, 1991, 340.- Avery. Charles, Giambologna. The completed sculpture Oxford,1987, $\mathrm{n}^{\circ}$ 27.GIAMBOLOGNA, gli dei,gli eroi.Firenze Musei, 2006, Cát. 2.

AEA, LXXX, 317, ENERO-MARZO, 85-106 2007, ISSN: 0004-0428 
Recientemente, por noticias de $\mathrm{M}^{\mathrm{a}}$ Dolores del Campo, de la Universidad de León, que me cedió generosamente y por las que pude localizar los documentos en los que se basa este breve trabajo,se ha confirmado su envio por García de Toledo en 1571 pero sobre todo algo que no se sabía, su autor. En efecto, según los epígrafes de una serie de documentos que dicha Doctora recogió en el Archivo Ducal de Medina Sidonia, el año de 1571 el Marqués de Villafranca, que en esos años era el citado Don García de Toledo, envia al Rey 39 cajas de mármoles y una fuente de mármol. Hacia el año de 1569 se da noticia que la hace, para Don García, Francisco "Moschilo" en Pisa y que han tomado medidas para su transporte 3 .

El Archivo Ducal de Medina Sidonia nos proporcionó amablemente alguno de los documentos bajo estos epígrafes, dada la imposibilidad de su consulta personal en éstos momentos por hallarse en trámites de digitalización. De ellos se desprende que el Moschilo, como le llaman en estos documentos, está trabajando en la fuente para don García desde el año de 1569 que pide, por carta sin fecha pero incluida en el legajo de este año, se le mande la tazze. e altri pezzi di marmi que si ritrovane costi a la marina, para poder acelerar el encargo , maestro al que debe referirse el encargo a Fernán López de que entregue a Orazio Estafero 6 julios para que vaya a Pietra Santa a llevar un despacho para el maestro que hace la fuente en los vaños, sin duda lugar referido a la pequeña villa de los Bagni di Lucca, junto a Massa y Carrara, el 29 de julio de 1569 siendo este mismo Fernán López el que se ocupa de pagar en 12 de julio de éste año las tuberías de plomo para la fuente, nota ésta última incluida al parecer en la carpetilla de los gastos que Don García hizo en Lucca.

Se han podido comprobar estos datos en las noticias dadas por el Vasari y recogidas por Venturi que en su día no se habían relacionado con la fuente de Aranjuez 4 .

Vasari, en su vida sobre Simone Mosca aclara como su hijo, Francisco llamado el Moschino, colabora en varias de sus obras y se le nombra su sucesor, a su muerte en 1554, de las que tenía encargadas en la Catedral de Orvieto, en donde se conserva su San Sebastián de mármol, desnudo, que hacía pareja con el Cristo con la cruz a la espalda, también de mármol y desnudo que lleva a cabo Rafael de Montelupo, el antiguo colaborador de Bartolomé Ordóñez. Por circunstancias no claras Francesco cede esta obra de Orvieto precisamente a Montelupo pero da noticias de otras obras de este escultor, especialmente las que se le encargan en la Catedral de Pisa ciudad en la que muere el año de 1578. Milanese, añade en nota a esta edición del Vasari que si retrae ancora che il Moschino attendeva a un lavoro per don Garzia de Toledo fratello Della duchesa Eleanora moglie de Cósimo ...Nel 74 e'a Torino. ${ }^{5}$

Venturi recoge las noticias del Vasari y además habla de una Venus mencionada por el Duque Cósimo como obra realizada por Moschino el año de 1564, que no se sabe si se refiere a la de la fuente para don García de Toledo pero aclara que el año de 1569 el Moschino ha terminado dos fuentes para el Duque y atiende los trabajos para don García de Toledo, hermano de la Duquesa Eleanora. ${ }^{6}$.

Estas noticias confirman que el "Moschilo" citado en los documentos del Archivo Ducal de Medina Sidonia es el Francesco Moschino, hijo de Simone Mosca, que trabaja precisamente en Pisa donde muere. La descripción de la obra que aparece en los documentos del Archivo General de Simancas proporcionada por Martín González, como se dijo en su día y confirma el grabado que adorna la bella publicación de Les Délices de l'Espagne 7 informa (fig. 3) que la fuente constaba de una serie de gradas y que en su pedestal

\footnotetext{
3 ADMS años 1569-1570, el documento sobre "Moschilo" Índice 12, n 4364. Se habló con el Archivo Ducal sito en Sanlúcar de Barrameda y amablemente nos proporcionaron los documentos que seleccionaron de nuestro pedido, aclarando en nota que los pagos sobre unas tuberías y el despacho dirigido al maestro que hace la fuente se incluyen en la carpetilla de los Gastos que Don García hace en Pisa y Lucca.

4 Vasari, Giorgio: Le vite de piu eccelenti Pittori, Scultori ed Architettori. Con anotaciones y comentarios por Gaetano Milanese, Firenza, VI, 305 y ss. - Venturi, Adolfo: La Scultura del Cinquecento.Parte III. Storia dell 'Arte Italiana. 1937 (Reprint Kraus, 1967), 969.

5 VASARI, cit 311.

6 VeNTURI, cit. 969.

${ }^{7}$ Martín GonzÁlez. Cit. 129, nota 106.- Álvarez De Colmenar, Juan. Les Délices de l'Espagne oú on voit... A. Leide, 1715.(1 ${ }^{\mathrm{a}}$ ed.1707), 59. Recogido por Estella, Margarita. "Decoración escultórica de los Jardines Reales del siglo XVI al XVIII según el texto de Alvarez de Colmenar (1707) y su estado actual", Struggle for Síntesis. The Total Work of Art in the 17th and 18th Centuries, Braga, 1996, 451-462, en p. 454., fig.1.
} 

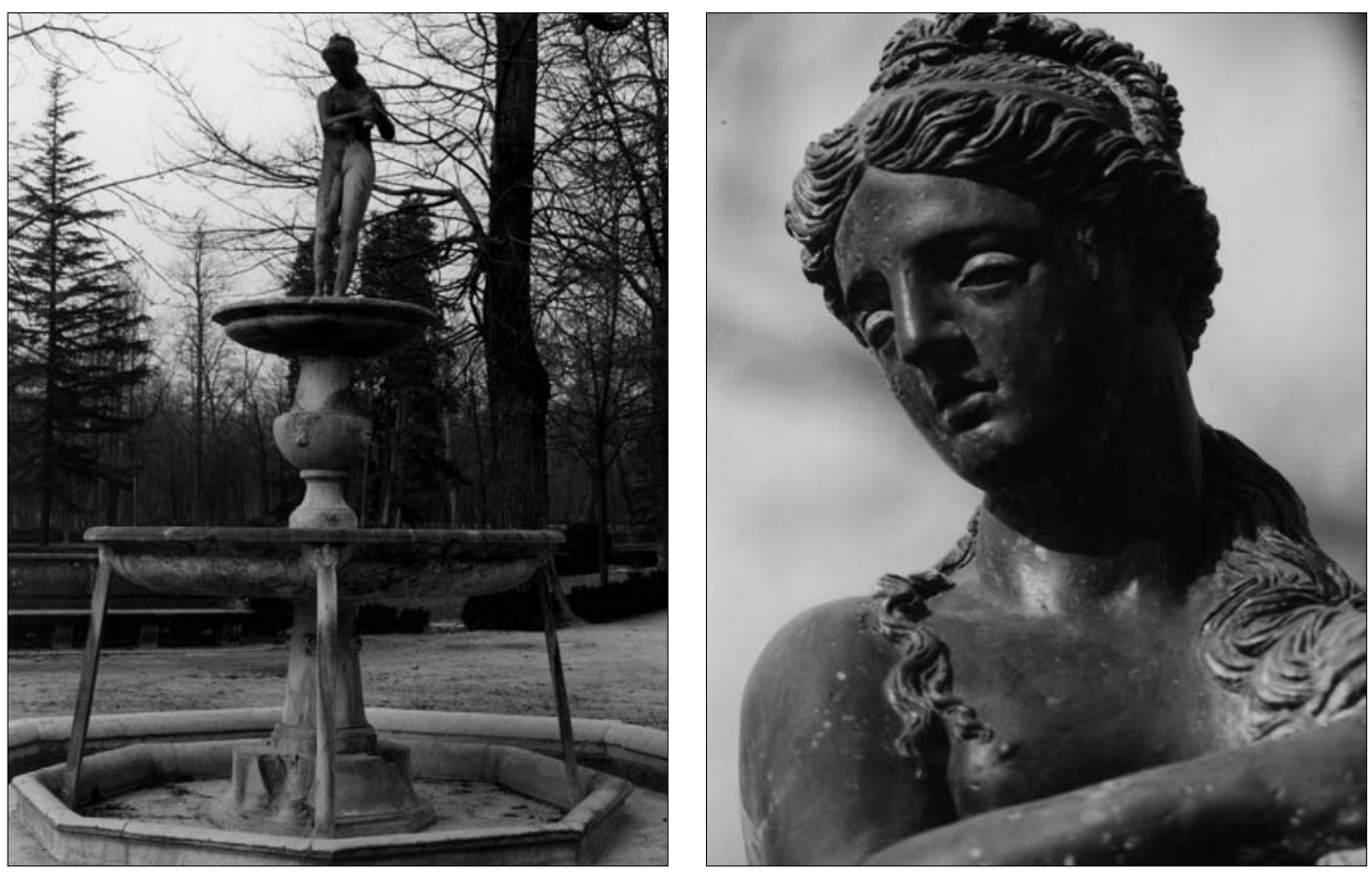

Figs. 1 y 2. Francisco Moschino. Fuente de la Venus secándose el cabello, Aranjuez. Jardines de la Isla.

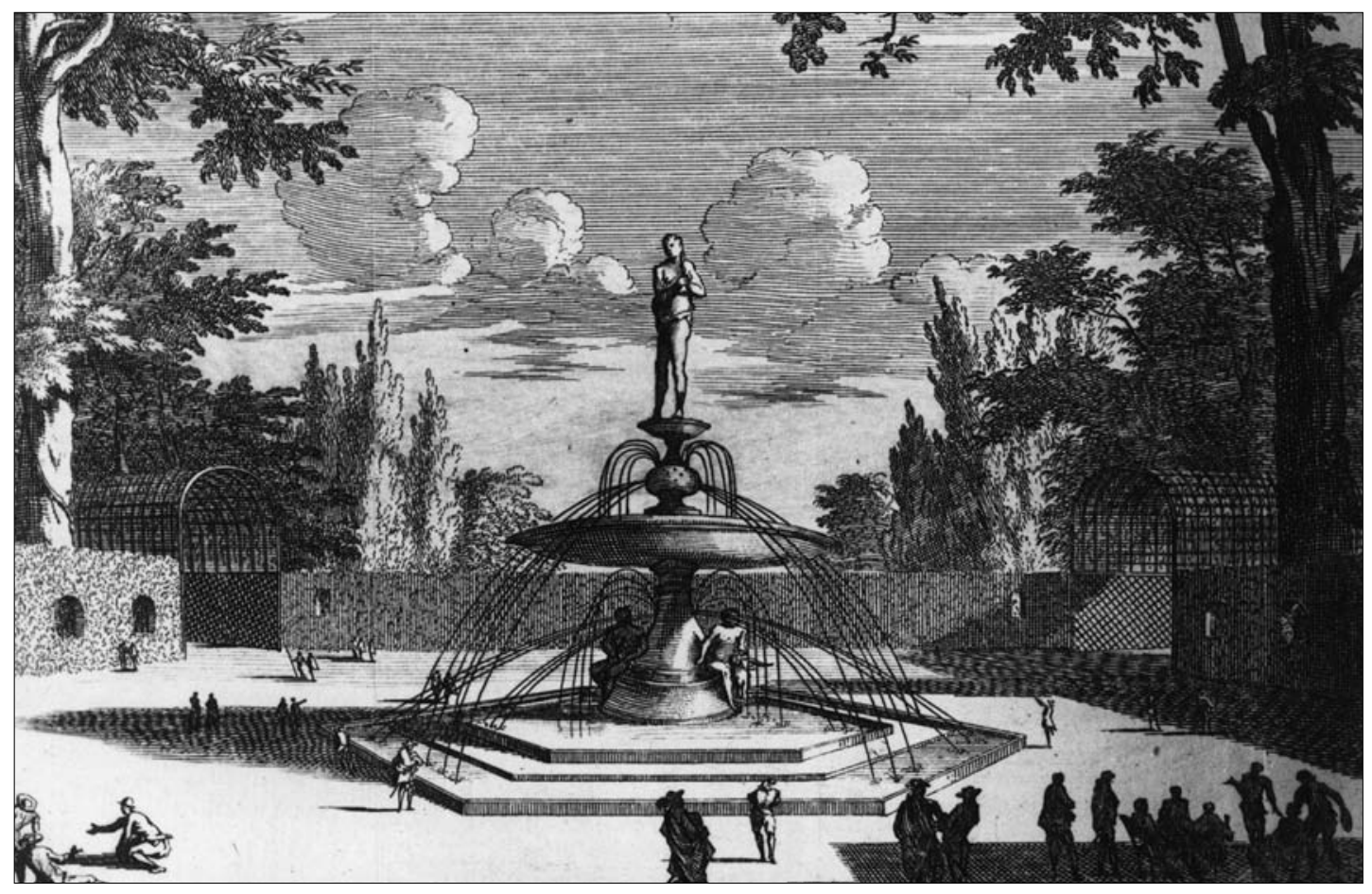

Fig. 3. Fuente de la Venus secándose el cabello, grabado en Álvarez de Colmenar, Les Délices del'Espagne, 1715.

AEA, LXXX, 317, ENERO-MARZO, 85-106 2007, ISSN: 0004-0428 
ochavado aparecían las figuras de cuatro muchachos con aves en la mano, parte de la fuente que no se conserva. Sus distintas tazas, la superior veteada posiblemente mischio, aparecían coronadas por la figura de bronce de una mujer secándose los cabellos, descripción que conviene perfectamente a la Venus que aún se conserva, la única y enigmática pieza de la fuente encargada a Moschino.

Se estudió esta importante escultura en bronce pero a la vista de los datos mencionados no puede afirmarse que también fuera obra de Moschino. Las escasas, de mala calidad y antiguas reproducciones de las obras de Francesco Moschino que conocemos no permiten un estudio comparativo pero nos parece, con las limitaciones dichas, que la Venus de bronce no recuerda demasiado su estilo por lo que pudo ser encargada a otro escultor más adiestrado en la obra de bronce.

Entre otros epígrafes de los documentos del Archivo Ducal de Medina Sidonia se mencionan los gastos hechos por don Garcia de Toledo en Pisa y Luca ${ }^{8}$ que deben referirse, al menos los de Pisa, a los debidos a la realización de la fuente sin conocer, por ahora, cuáles fueron los ocasionados en Luca.

Se revisaron los posibles escultores que tuvieron relación con el Moschino y que conocían el trabajo del bronce, como el citado Raffelo de Montelupo con estancias conocidas en Lucca. No conocemos su citado Cristo que pudiera servir de término de comparación con la Venus de bronce de Aranjuez por lo que también se ha intentado buscar el nombre de otros artistas que pudieran trabajar en bronce quizás en Lucca, donde en su día se trabajó el bronce por artistas de la categoría de Della Quercia ya que las noticias del archivo ducal indican que Don García de Toledo efectuó pagos en esta ciudad. Ya se ha hablado de Raffaelo de Montelupo, colaborador del Moschino en Orvieto que como su hermano Baccio era conocedor de la técnica del bronce y se sabe que ambos habían trabajado en Lucca, ciudad que como dicen los historiadores del arte se nutre desde la segunda mitad del siglo XVI de artistas extranjeros .

Quizás es más sugerente la relación que pudo tener el Moschino con la saga de los Lorenzi que, naturales de Settignano la patria del Fancelli, tan conocido en España, trabajaron en fuentes decoradas con figuras en bronce. Uno de sus miembros, Antonio Lorenzi trabaja en Pisa y se conoce la colaboración de Stoldo Lorenzi , que había llevado a cabo en 1565 la fuente de Neptuno en bronce para Cósimo de Médicis, con el Moschino en la Capilla de San Rainero de la Catedral de Orvieto, obra en mámol. También la Sra Wiles dio a conocer que Giovanni Battista Lorenzi, en el círculo de artistas de la corte de Cósimo de Médicis, se ocupa de una fuente de mármol destinada a un caballero español del que no se dice el nombre, quizás del entorno del Virrey don Pedro de Toledo, pero cuya composición difería de la que presentaba la fuente de la Venus de Aranjuez de la que nos ocupamos. Precisamente esta autora aumenta la lista conocida de obras del Moschino con el encargo de dos fuentes para la reina de Francia y otra fuente que llevó a cabo para la ciudad de Parma ${ }^{9}$ reprodujo algunas obras de los Lorenzi que como el grupo de Arethusa de Battista recordaban la obra de Aranjuez, menos similar a la bella Galatea de bronce de Stoldo. La noticia dada últimamente por la Dra Boström sobre una escultura perdida, de tema y material desconocidos, realizada por Stoldo Lorenzi y que doña Eleanora de Toledo, la esposa de Cósimo de Médicis, regala a su hermano el mencionado García de Toledo, Virrey de Sicilia que al parecer se la lleva "al sur"parece apoyar nuestra sugerencia ${ }^{10}$.

Precisamente, la citada $\operatorname{Dr}^{\mathrm{a}}$ Boström, que no conoce la documentación que aportamos en esta nota, ha atribuido recientemente la escultura de nuestra Venus de Aranjuez al escultor broncista Zanobi Lastricati por el parecido que presenta con el Mercurio en bronce, obra de este artista,hoy en la Walters Art Gallery de Baltimore. Conocido fundidor de pequeñas obras en bronce, este escultor trabaja en el círculo de artistas de la Corte de los Médicis, pero la Doctora Isabella Lapi Ballerini no considera muy convincente la atribución. A nuestro parecer, la cronología anterior, de hacía 1550, del artista parece dar la razón a esta última,pero por otra parte la Doctora Boström apunta además una serie de consideraciones de gran interés en este campo de

\footnotetext{
8 ADMS, Año $1569, \mathrm{n}^{\circ} 1225$.

${ }^{9}$ Venturi,cit. X, $2^{\mathrm{a}}$ p, Milán 1936: sobre los Montelupo y sobre los Lorenzi (441-460).-WILES, Bertha Harris. The fountains of florentine sculptors from Donatello to Bernini, Cambridge 1933, 138, appendix B (fuentes perdidas); fig. 193 la Arethusa.

${ }^{10}$ BoströM,Antonia. "A new addition to Zanobi Lastricati:Fiorenza or the Venus Anadyomene: the fluidity of iconography”, The Sculpture Journal, I, 1997, 1-6, p.1, nota7.
} 
Fig. 4. Giovan Vincenzo Casale. Proyecto de una fuente. Madrid, Biblioteca Nacional.

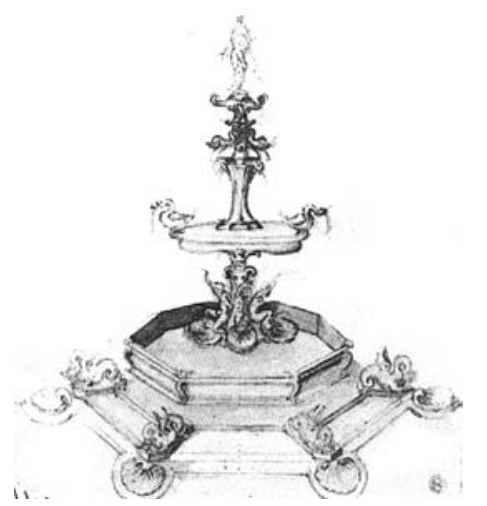

la fundición en bronce de obras que diseñadas por grandes artistas se lleva a efecto en la realidad por estos artistas menores que pululan en Florencia entre cuyos nombres quizás pudiese localizarse al autor de nuestraVenus ${ }^{11}$.

No se ha podidosolucionar el problema de esta Venus de bronce pero a la espera de que algún día se aclare con nueva documentación al menos se ha localizado el autor del conjunto de esta emblemática fuente de los Jardines de la Isla en Aranjuez y proporcionado un dato más sobre el mecenazgo que lideran en Italia las grandes familias españoles del entorno de la Corte Virreinal de Nápoles, en este caso la de los Toledo. La figura de don García de Toledo es de gran interés para este estudio por sus grandes empresas jardínísticas tanto en su villa de Chiaia como en la de Pozzuoli que pudieron influir en la organización de los Jardines de Aranjuez como apunta su envio de la Fuente de la Venus. El Album de dibujos de Giovanni Vincenzo Casale de la Bilioteca Nacional reproduce el estudio de una fuente del giardino de don gartia de Toledo en Pozzuolo y más adelante presenta otro bello proyecto de Fuente (Fig. 4) cuya composición recuerda mucho a la de la Venus de Aranjuez, que quizás pudo conocer el artista en su estancia en Madrid ${ }^{12}$.

MARgarita M. Estella

11 BoströM, cit.- LAPI BALLERINI, Isabella, Fiorenza,cat.2, Giambologna, gli dei, gli eroi, cit.

12 Dibujos de Arquitectura y Ornamentación de la Biblioteca Nacional Siglos XVI y XVII Madrid., 1991. Catálogo por Elena Santiago. Texto sobre Álbum de Casale, Fernando Marías y Agustín Bustamante. Cat. c19 (el de Pozzuolo), c21. 